\title{
Seeing animal welfare from two sides
}

\author{
Cindy M. Hoorn, DVM, PhD, Director, Global Regulatory Compliance, \\ Pfizer Worldwide Comparative Medicine, Groton, CT.
}

\begin{abstract}
Dr. Hoorn talks about how her experiences as a veterinarian and a researcher led her to her true calling.
\end{abstract}

\begin{abstract}
After working as a clinical veterinarian, you decided to pursue a PhD in Pharmacology and Toxicology, and you worked as a research scientist in the field of mechanistic toxicology for several years. What inspired your interest in research?

I definitely see my career path as an evolution. I went into veterinary medicine with the simple wish to take care of animals. I didn't realize that what would intrigue me most was the science behind the medicine. Moving into biomedical research seemed like a natural progression for me. I was first exposed to research when, as an me with a great opportunity to use my skills in a new and integrated way. I had the veterinary knowledge and experience to understand the importance of animal care and welfare, but I also had experience as a researcher, with a high-level understanding of basic science and the scientific process, so I was able to see IACUC issues from both sides. I was able to consider all kinds of science from a 'big picture' perspective, and I also found that the administrative and team-building skills I'd learned along the way were a great asset in dealing with both investigators and veterinarians in a research setting.
\end{abstract} undergraduate at Michigan State, I took a course called 'Experiments in Zoology', and I quickly became hooked. As a result, I spent the summer after my first year of veterinary school working in a parasitology lab, and the following summer I worked on a project involving the effects of a plantderived toxin on the vascular system. My advisor saw great potential for applying the foundation of a veterinary medical education to the field of biomedical research. After finishing veterinary school, I took a job in a small animal practice, and while I learned a lot, I really wanted to get back to research. If I had not had these wonderful opportunities to experience research first-hand, I would probably not have considered this career path when I was looking for a change.

Your career interests have since shifted towards regulatory and animal welfare issues. How do you think your experiences working as both a veterinarian and a research scientist have helped you in your current work? Working in regulatory oversight turned out to be a great fit for me and provided

\section{Describe your career path at Pfizer.}

About 15 years ago, there was a realization at Pfizer that institutional oversight of animal care and use needed to step up to meet the steadily rising expectations of regulatory agencies and the public and that, for this oversight role, they really needed a professional that was somewhat removed from the comparative medicine organization. I was fortunate enough to step into this new role of 'IACUC Officer' and create it from the ground up. I spent about ten years building the IACUC and all the associated processes and procedures at our Kalamazoo site. I've always seen the role of the IACUC as one of facilitating compliance, and it was important to me to build relationships with the scientists, the veterinarians, the animal care staff and the institutional leadership.

As we became a larger company with several diverse sites around the globe, it also became important to me to find a way

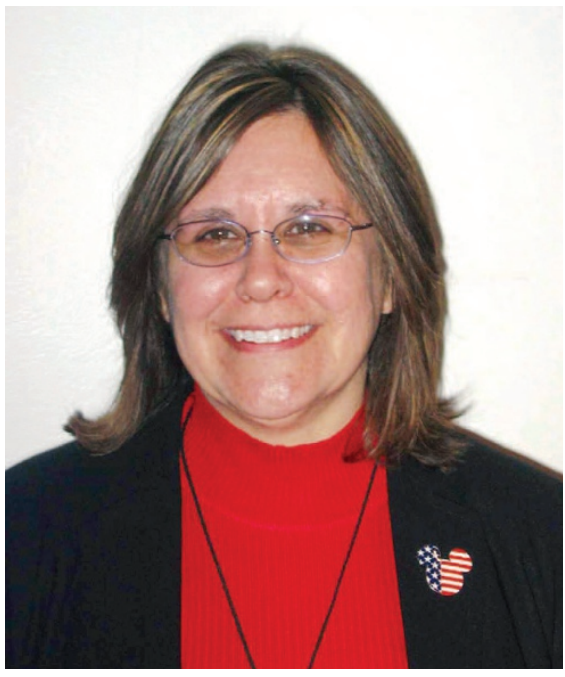

to work with my colleagues at those sites to share good practices and support one another. I was very proud to be a part of establishing a global IACUC Council across Pfizer and also to lead the Pfizer Animal Issues Management team to ensure that our practices were consistent across the company and that we spoke with one voice when asked to communicate on issues related to animal care and welfare. When I joined the Global Regulatory Compliance organization in Worldwide Comparative Medicine, I once again was able to create a new role for myself with an emphasis on the things I've come to do best and enjoy most-communication and outreach — both internally across Pfizer and externally to our various partners, stakeholders and the public.

\section{Is there anything else you would like} to share with Lab Animal readers?

Despite the best-laid plans, we really can't see all that far down the road when it comes to our lives and careers. I can't emphasize enough just how important it is to keep an open mind and make the most of every experience and every relationship along the way. If someone offers a helping hand, take it. Start building your own network and use it! In time, the lines will blur and it will be hard to distinguish your work relationships from your friendships. When that happens, you'll know that you no longer have 'just a job' but have found your calling. 